\title{
Mycoflora and production of wine from fruits of soursop (Annona Muricata L.)
}

\author{
Raphael N Okigbo' \\ Omokaro Obire ${ }^{2}$ \\ 'Department of Botany, Nnamdi \\ Azikiwe University, Awka, Anambra \\ State, Nigeria; ${ }^{2}$ Department of Applied \\ and Environmental Biology, Rivers \\ State University of Science and \\ Technology, Port Harcourt, Nigeria
}

Correspondence: $\mathrm{R} N$ Okigbo Department of Botany, Nnamdi Azikiwe University, P.M.B. 5025, Awka, Anambra State, Nigeria

Email okigborn17@yahoo.com www. nigeriaknowledgecenter.net

\begin{abstract}
An investigation was conducted on the mycoflora associated with the different parts of fresh and rotten fruits of soursop (Annona muricata L.) and the potential of using both indigenous yeast flora and commercial yeast extract for wine production. Isolation of fungi and pathogenicity test were carried out with Sabouraud dextrose agar. Mycoflora were more in the rotten fruits than in the fresh fruits. Botryodiplodia theobromae was isolated only from the rotten fruits (skin) while Trichoderma viride was isolated only from the fresh fruits. Penicillium sp., was the most dominant in all the fruit part of fresh soursop fruit with Rhizopus stolonifer having the highest percentage occurrence (36.39\%) in the rotten fruit. Most of the isolated fungi indicated occurrence of such common airborne fungi on soursop fruits and the potential to induce rot in fresh healthy fruits of soursop in storage. Soursop juice was fermented for 10 days and wine was obtained. There was a significant difference $(\mathrm{P}<0.05)$ in the alcoholic content of the wines obtained from the indigenous and commercial yeasts. The wine obtained from the pasteurized, ameliorated soursop juice inoculated with propagated indigenous yeast yielded the highest alcoholic content. Based on the level of the nutritional composition of soursop juice, the ability to support yeast growth, the high alcoholic content and palatability of the wine, the Annona muricata is good source for wine production and single-cell protein.
\end{abstract}

Keywords: fermentation, fruit yeast, fungi, incidence, rot

\section{Introduction}

Soursop also known as guanabana (Annona muricata L.) belonging to the family Annonaceae and indigenous to tropical north and south America is one of the exotic fruits prized for its very pleasant, sub-acid, aromatic and juicy flesh which consists of edible white pulp and a core of indigestible black seeds. ${ }^{1-5}$ However, it is highly susceptible to spoilage, softens very rapidly during ripening, and becomes mushy and difficult to consume fresh. It is sold in local markets and is rejected at market because of external injuries or uneven shape and size. ${ }^{6,7}$ It produces large heart-shaped edible fruit of various sizes (average fruit weight is about $0.5 \mathrm{~kg}$ ) yellow green in color with white flesh. ${ }^{8}$ Thus, soursop has many therapeutic properties; the juice is diuretic while the other parts have antibacterial, anticancerous, astringent, sedative, and other properties. ${ }^{9}$ Soursop, like other tropical fruits, serves as a potential source of raw materials for fruit products such as juice, beverages, wine, jellies, jam puree, power fruit bars, and flakes. ${ }^{7,10}$

The economic and nutritional importance of fruits to Nigerians cannot be overemphasized. ${ }^{11}$ It is a major source of income for many farmers who cultivate them for fresh produce markets. It also provides a source of nutrients and play important role in the diet of many people living in the tropics by raising its nutritional value through the provision of essential minerals and vitamins and addition of flavors, colors and variety to the diet and equally by contributing to the proteins and calories contents of the diet, ${ }^{11,12}$ for instance, the food value per $100 \mathrm{~g}$ edible portion of soursop contains $29.6 \mathrm{mg}$ of 
ascorbic acid, $11 \mathrm{mg}$ of trytophan, $11.00 \mathrm{~g}$ of protein, $14.63 \mathrm{~g}$ of carbohydrates, and a lot of sugar, etc. ${ }^{13}$ Hence, the fruit is nutritionally high in carbohydrates, particularly fructose, and contains significant amounts of vitamin $\mathrm{C}$, vitamin $\mathrm{B} 1$, and vitamin B2. ${ }^{13}$ However, adverse physical and biochemical changes in these fruits tissues can lower acceptability and nutritional value. ${ }^{11,14}$ Generally, loss in nutritional value of fruits is brought about by contamination by different microorganisms either before harvest (preharvest deterioration) or after harvest (postharvest deterioration). ${ }^{13}$ In other words, the most frequent reasons for quality deterioration of food products is the result of microbial activity and this often results in food molding, fermentation, and change in acidity. ${ }^{15}$

More often than not, the tissue of normal healthy fruits is generally without experimental evidence considered to be sterile although occurrences of microorganisms in different parts of fresh fruits have been reported by some workers. ${ }^{12}$ The presence of these microorganisms has also shown to occur at any stage from standing crop through to harvest handling operation until they reach the consumer. ${ }^{16}$ In these crops also, Joffe ${ }^{17}$ and McDonald ${ }^{18}$ reported that fungal contamination is most prevalent and that fungi are their most important pathogens. Therefore, the occurrence of mycoflora as a type of microorganism and as the prevalent organisms in fruits is of primary importance in this study as some of these mycoflora have the potential to produce mycotoxins (secondary metabolites of fungi which are toxic and/or carcinogenic in some cases. ${ }^{19}$ For example, many infertility cases and other infections such as aspergillosis, etc., have been traced to be caused by some mycoflora although their toxicity depends on the species and level of exposure.

Fermentation is a relatively simple natural, efficient, inexpensive, and low-energy food preservation process that reduces the need for refrigeration. ${ }^{20}$ It is used industrially for the manufacture of certain beverages by the action of yeasts, bacteria, or other microorganisms. ${ }^{21}$ Strains of the yeast Saccharomyces cerevisiae (Bakers' yeast) within the family Saccharomycetaceae of the class Ascomycetes are generally used for the production of wine, beer and bread. ${ }^{22}$ Wine is the alcoholic product of any fermentation fruit or vegetable liquor. ${ }^{21,23,24}$ Moreover, according to various investigations on the fermentation of fruit juices, it has been reported that they could be used as feed-stocks for the production of single-cell protein (SCP) based on their level of sugar and the ability to support the growth of yeasts. ${ }^{7,24,25}$ Single-cell protein thus, are the dried cells of microorganisms such as yeast that could be grown in large-scale culture systems for use as protein for human or animal consumption. ${ }^{20,26}$
Postharvest losses which are the thorny problems hampering the agricultural development in Nigeria, where current estimates of postharvest loses of fruits stand at over $60 \% .{ }^{27}$ Moreover, nutrient depletion, quality loss, and damage of physiological structures before consumption or converting into secondary products also result. ${ }^{28,29}$

Moreover, the production of fruit crops in Nigeria is seasonal, thus, there is a need to preserve and store them from time of harvest through the period of scarcity, for the purpose of retaining them as foods and articles of trade. ${ }^{27}$ Information on the mycoflora associated with soursop (Annona muricata L.) fruit is scanty and occurrence in the rotten fruits of the plant has not been documented in this part of the world. This work, therefore investigates the different mycoflora associated with soursop fruits and how to preserve soursop fruit juice through an alcoholic fermentation and also shows the ability of soursop juice to support yeast growth.

\section{Materials and methods}

\section{Sources of materials}

Fresh healthy and rotten soursop fruits of various sizes were collected from soursop trees in home gardens at Ekwulobia and Awka towns in Anambra State and Umunede in Delta State, Nigeria. The plant was authenticated in the Department of Botany, Nnamdi Azikiwe University, Awka, Nigeria.

These fruits were refrigerated until required for the analysis whereas those for rotten fruits analysis were packaged in polyethylene bags and taken to the laboratory where they were kept until needed.

\section{Isolation, characterization and identification of mycoflora from the fruits \\ Determination and isolation of fungal \\ pathogens from the skin}

Three fresh fruits were rinsed in sterilized water, surface sterilized with $70 \%$ ethanol. Sterile gloves were worn and with the aid of a sterile forceps, the skins of the washed fruits were peeled off into three sterile Petri dishes for each fresh fruit. Discs of the peeled skins were then made with the aid of a sterile cork borer ( $5 \mathrm{~mm}$ in diameter). The discs were dried on sterile filter papers and plates on appropriate media prepared above. Three plates were used for each fresh fruit and three discs were plated on each. Incubation was at $28 \pm 2{ }^{\circ} \mathrm{C}$ for $2-5$ days for yeast and moulds. Observations were made for emergence of colonies. This method was also 
used for the determination of the fungal pathogens within the skin of the rotten fruit.

\section{Determination and isolation of fungal pathogens from the pulp}

Three fresh fruits were thoroughly washed with sterile water after which the surface of the skins was sterilized with $70 \%$ ethanol. With the aid of sterile forceps and sterile gloves worn, the fruits were hand peeled; small strips of each of the pulp of the three fruits were obtained aseptically and plated. Pulps from each fruit were plated separately in three different Petri dishes (three strips to a plate) in the already prepared media (Sabourand dextrose agar [SDA] incorporated with streptomycin). This was also done to the pulp of the rotten fruits.

\section{Determination of the juice mycoflora}

Fresh fully ripe soursop fruits were washed using sterile water and the outer skins surface also sterilized with $70 \%$ ethanol. The fruits were hand peeled, decored, deseeded, and the pulp blended using an electric blender. Little water was added to facilitate the blending process. The pulps were filtered using muslin cloths. The filtrates were poured into three sterile tubes (one tube for the filtrate of each fruit). Discs ( $5 \mathrm{~mm}$ in diameter) of sterile filter papers were inserted into the filtrates and were allowed to stand for about 10 minutes. They were removed and plated into the SDA incorporated with streptomycin (three discs per plate). Three plates of the solidified media were inoculated for each of the filtrate. The inoculated plates were incubated at $28 \pm 2{ }^{\circ} \mathrm{C}$ and observations were made daily for growth of fungi. The same was done to the rotten fruit juice.

\section{Determination of the mycoflora from the seeds}

The fruits were washed and surface sterilized with sterile water and $70 \%$ ethanol, respectively. With the aid of sterile gloves and sterile knife, the fruits were cut into bits and were deseeded. They were passed through $70 \%$ ethanol and were plated as usual. Incubation and inoculation were done as previously. The seeds from the rotten fruits were equally treated as such.

\section{Determination of percentage occurrence of the fungal isolates}

This was done to determine the incidence of occurrence of the different fungal isolates. The frequency of occurrence of the pathogens from the seed, juice, pulp, and skin of the soursop fruits were determined. The total number of each isolate in all samples was obtained against the total number of all the isolates in all the samples screened. The mean value of this gives the percentage of occurrence as the following equation shows:

$$
\% \text { of occurrence }=\mathrm{X} / \mathrm{N} \times 100
$$

where $\mathrm{X}=$ total number of each isolate in all samples and $\mathrm{N}=$ total number of all the isolates in all the samples.

\section{Identification of isolated fungi}

The identification of the isolated fungi was done both macroscopically and microscopically. The gross morphology of the fungal growth on plates was studied including their colors. Later small portions of the fungal pure culture were teased and mounted in lactophenol in cotton blue dye on a clean slide and covered with a clean cover slip and observed under the microscope. The identity of the fungi were certified using cultural and pathogenicity tests as well as comparing them with confirmed representative identified by means of keys. ${ }^{30,31}$ The incidence of occurrence of each fungus was calculated using a formula. ${ }^{32}$

\section{Pathogenicity test}

Freshly harvested clean noninfected (mature) soursop fruits were washed with sterile surface sterilized by swabbing with 70\% ethanol and holes were bored in them using a sterile cork-borer ( $5 \mathrm{~mm}$ in diameter). Another sterile cork borer was used to cut pellets of agar containing 3-5-day-old cultures of fungal mycelia of the isolates, which were used to inoculate the hole created by scooping out soursop tissue. The scooped out tissues were replaced to cover the borehole. The inoculated fruits were sealed with vaseline on those points where the holes were made. They were then enclosed in polyethylene bags containing moist cotton wool to maintain high relative humidity and incubated at $28 \pm 2{ }^{\circ} \mathrm{C}$ for seven days. The extent of rot was determined by measuring the size of infection (mm). Wet mounts of hyphal/asexual structures obtained from these infected materials were stained with lactophenol in cotton blue dye and viewed under the compound microscope for the presence of the pathogen and identified and certified as described above.

\section{Soursop juice extraction}

Five fruits weighing $3.5 \mathrm{~kg}$ were washed thoroughly with $70 \%$ ethanol. The fruits were peeled with sterile knife to remove the skin and later the seeds were removed, after they were extracted with an electric juice extractor (Binatone, England), one thousand milliliters of water was added to facilitate the grinding and the extraction because the juice was very thick. The two liters of extracted juice was poured into a sterile container previously rinsed with $2 \%$ sodium metabisulphite. 


\section{Fermentation of soursop juice}

Yeast identification, isolation, and propagation

The indigenous yeast flora to be used for fermentation was first isolated from two-days fermented soursop juice. The juice was aseptically inoculated with streak plate technique on SDA (Biotech, UK) incorporated with $500 \mathrm{mg}$ of chloramphenicol capsule per plate. The plates were incubated inverted at $21{ }^{\circ} \mathrm{C}$ for 24 hours. The yeast present was identified using a manual..$^{33}$ Furthermore, the yeast strain identified was incubated in pure culture in test tubes, stored in slants and refrigerated (Thermacool) at $4{ }^{\circ} \mathrm{C}$.

\section{Fermentation of soursop with indigenous yeast flora}

Three experiments with three replicates each were carried out. The quantity of soursop juice used was $450 \mathrm{ml}$. Before the experiments started, $20 \%, 30 \%, 40 \%$, and $50 \%$ dilution of the juice was carried out as a result of the thickness of the soursop juice, respectively. Finally, 50\% dilution gave the desired result, thus $900 \mathrm{ml}$ soursop juice that resulted was then used for the experiments.

For the first experiment, the soursop juice was allowed to ferment naturally. One hundred milliliters of juice was poured into a sterile bottle with three replicates. They were covered with cotton wool and allowed to stand for 36 hours for aeration (plate 4). After this, the bottles were tightly corked and left at room temperature to ferment for 10 days. Sampling for yeast count was done with SDA (Biotech) and the yeasts were counted with Digital Colony Counter (Labtech) at two-day intervals. The $\mathrm{pH}$ and alcoholic content were determined on a daily basis.

For the second experiment, there was an amelioration of the juice with $15 \mathrm{~g} / 100 \mathrm{ml}$ commercial sucrose. Hundred milliliters of juice was poured into a sterile bottle with three replicates. They were supplemented with $15 \mathrm{~g} / 100 \mathrm{mg}$ of commercial sucrose and shaken thoroughly. Aeration was allowed by covering the bottles with cotton wool and left to stand for 36 hours. They were later tightly corked with the bottle covers and left to stand at room temperature for 10 days fermentation. Sampling for yeast count was done at two-day intervals. The $\mathrm{pH}$ and alcoholic content were determined on a daily basis.

For the third experiment, the soursop juice was pasteurized in a water bath (GFL, Germany) at $64{ }^{\circ} \mathrm{C}$ for 30 minutes then rapidly cooled. One hundred milliliters of the soursop juice was poured into a sterile bottle with three replicates. Amelioration was carried out by adding $15 \mathrm{~g} / 100 \mathrm{ml}$ of commercial sucrose and accessory nutrients; $0.08 \mathrm{~g}$ potassium dihydrogen orthophosphate $\left(\mathrm{KH}_{2} \mathrm{PO}_{4}\right), 0.06 \mathrm{~g}$ ammonium sulphate, and $0.02 \mathrm{~g}$ sodium metabisulphite was used as a stabilizer and antioxidant. After thorough stirring of the juice, the inoculums which is $25 \mathrm{ml}$ of propagated yeast per 100 $\mathrm{ml}$ was introduced into the pasteurized juice. Aeration was allowed by lightly covering the bottles with cotton wool for 24 hours, after which it was removed and tightly covered with the bottle cover and allowed to ferment for 10 days at room temperature. Sampling for yeast count was done at two-day intervals. The $\mathrm{pH}$ and alcoholic content were determined on a daily basis.

Finally, the soursop wine obtained at the end of the fermentation was run off into a clean bottle previously rinsed with $1 \%$ sodium metabisulphite and preserved with $0.02 \mathrm{~g} / 100 \mathrm{ml}$ of sodium benzoate.

\section{Fermentation of soursop with commercial yeast extract}

Three experiments with three replicates each were carried out. Four hundred and fifty milliliters of soursop juice was used for the experiments. Dilution of the soursop juice was done, $20 \%, 30 \%, 40 \%$, and $50 \%$, respectively. Fifty percent gave the desired result, making $900 \mathrm{ml}$ of soursop juice.

For the first experiment, there was amelioration with $15 \mathrm{~g} / 100 \mathrm{ml}$ commercial sucrose. One hundred milliliters of juice was poured into a sterile bottle in three replicates, supplemented with $15 \mathrm{~g} / 100 \mathrm{ml}$ of commercial sucrose and stirred thoroughly to dissolve. One gram per $100 \mathrm{ml}$ of commercial yeast (Saccharomyces cerevisiae) was started off by addition of some warm of soursop juice and added to the juice once they started bubbling. The bottles were covered with cotton wool for 36 hours aeration. Then the bottles were then tightly corked and left at room temperature for 10 days of fermentation. Sampling for yeast count was carried out at two-day intervals. The $\mathrm{pH}$ and alcoholic content were determined on a daily basis.

For the second experiment, there was no addition of commercial sucrose to the soursop juice. One hundred milliliters of juice was poured into a sterile bottle in three replicates, $1 \mathrm{~g} / 100 \mathrm{ml}$ commercial yeast was started off and added once they started bubbling. Aeration was allowed for 36 hours by covering with cotton wool. They were then corked tightly for 10 days fermentation in a room temperature. Sampling of yeast count was done at two-day intervals. The $\mathrm{pH}$ and alcoholic content were determined on a daily basis.

For the third experiment, the soursop juice was pasteurized in a water bath (GFL, Germany) at $64{ }^{\circ} \mathrm{C}$ for 30 minutes, then rapidly cooled. One hundred milliliters of juice was poured into a sterile bottle with three replicates. 
They were supplemented with $15 \mathrm{~g} / 100 \mathrm{ml}$ of commercial sucrose and accessory nutrients: $0.08 \mathrm{~g}$ potassium dihydrogen orthophosphate $\left(\mathrm{KH}_{2} \mathrm{P}_{4}\right), 0.06 \mathrm{~g}$ ammonium sulphate and $0.02 \mathrm{~g}$ of sodium metabisulphate which was used as stabilizer and antioxidant. After thorough stirring, $1 \mathrm{~g} / 100 \mathrm{ml}$ of commercial yeast, which was started off in some warm soursop juice, was added immediately it started bubbling. Aeration was allowed by covering the bottles with cotton wool for 24 hours, after which they tightly corked and kept for 10 days fermentation at room temperature. Sampling for yeast count was done at two-day intervals. The $\mathrm{pH}$ and alcoholic content were determined on a daily basis.

Finally, the soursop wine obtained at the end of the fermentation was run off into a clean bottle previously rinsed with $1 \%$ sodium metabisulphite and preserved with $0.02 \mathrm{~g} / 100 \mathrm{ml}$ of sodium benzoate.

\section{Physicochemical analysis of soursop juice and soursop wine}

The moisture, protein, fat, ash, carbohydrates, fiber contents, titratable acidity ( $\mathrm{g}$ citric acid/100 g), $\mathrm{pH}$, sugar contents, specific gravity and alcohol content of the fresh soursop juice and wine were obtained using standard methods. ${ }^{34,35}$

\section{Statistical analysis}

The experimental design used was randomized complete block design. Analysis of variance (ANOVA) was used to compare the mean and Duncan's multiple range test (DMRT) was used to separate the means. ${ }^{32}$

\section{Results}

\section{Isolation and identification of fungi}

The fungi isolated from the different parts of both fresh and rotten soursop fruits showed that lesser species of fungi were isolated from the fresh fruit than the rotten fruit (Table 1). These included: Aspergillus niger, Candida sp., Fusarium sp., Rhizopus stolonifer, Penicillium sp., and Trichoderma viride while the isolated fungi from rotten fruit included $A$. niger, A. tamirii, A. flavus, Candida sp., Fusarium sp., Rhizopus sp., Pencillium sp., and B. theobromae. The incidence of $A$. niger and $R$. stolonifer were highest on both fruits types examined. In the rotten soursop fruits, A. flavus sp. occurred only on juice and pulp and was not isolated from the other different parts of the fruits. The fungus (A. flavus) was not isolated from the fresh soursop fruit either on the skin or on
Table I Mean percentage occurrence of mycoflora on different parts of rotten fruits of Annona muricata

\begin{tabular}{lllll}
\hline \multirow{2}{*}{ Fungi } & \multicolumn{4}{l}{ Parts of fruits } \\
\cline { 2 - 5 } & Juice (\%) & Pulp (\%) & Skin (\%) & Seed (\%) \\
\hline Aspergillus niger & 34.55 & 33.89 & 45.63 & 19.57 \\
Aspergillus tamirii & 3.03 & 11.85 & 3.44 & 0.00 \\
Aspergillus flavus & 1.01 & 2.22 & 0.00 & 0.00 \\
Candida sp. & 36.10 & 29.27 & 9.15 & 0.00 \\
Fusarium sp. & 6.59 & 18.00 & 5.93 & 24.98 \\
Rhizopus stolonifer & 14.90 & 4.78 & 26.33 & 31.56 \\
Penicillium sp. & 3.68 & 0.00 & 3.52 & 24.11 \\
B. theobromae & 0.00 & 0.00 & 8.70 & 0.00 \\
\hline
\end{tabular}

other parts of the fresh fruits (Table 2). Some fungi were found to be localized in certain parts of the fruit as well as in a particular fruit. $B$. theobromae was isolated only from the skin of the rotten fruits while A. flavus, A. tamirii occurred only on the rotten fruit (Tables 1,2). Trichoderma viride was isolated only from the fresh fruit (from the juice, pulp, and skin) as seen in Table 2 while Candida sp. did not occur in the seed of the both fruit types (Tables 1, 2). Fusarium. sp., and Penicillium sp., had higher percentage occurrence in the seed of rotten fruits (24.98\% and $24.11 \%$ ) compared to $(16.52 \%$ and $14.81 \%)$ in the seeds of the fresh fruits (Table 1 ). The reverse is true for $R$. stolonifer with higher percentage occurrence in the skins $(92.59 \%)$ and seeds $(40.15 \%)$ of the fresh fruits than in the rotten fruit where it has $26.35 \%$ in the skin and $31.56 \%$ in the seeds. A. tamirii occurred in a very insignificant level of $4.69 \%$. More fungi were equally isolated from the juice of the fresh fruits than from the pulp, skin, and seed as seen in Table 3.

There was significant difference in the mycoflora incidence within the rotten and fresh soursop fruits and among the juice, pulp, skin, and seed at significant level of $\mathrm{P}<0.05$.

Table 2 Mean percentage occurrence of fungi within the fresh fruits of Annona muricata

\begin{tabular}{lllll}
\hline \multirow{2}{*}{ Fungi } & \multicolumn{4}{l}{ Parts of fruits } \\
\cline { 2 - 5 } & Juice (\%) & Pulp (\%) & Skin (\%) & Seed (\%) \\
\hline Aspergillus niger & 37.40 & 32.33 & 0.00 & $24.8 \mathrm{I}$ \\
Candida sp. & 20.54 & 15.66 & 0.00 & 0.00 \\
Fusarium sp. & 16.97 & 32.18 & 0.00 & 16.52 \\
Rhizopus stolonifer & 12.83 & 0.00 & 92.59 & 40.15 \\
Pencillium sp. & 3.10 & 7.41 & 7.41 & 14.81 \\
Trichoderma viride & 9.87 & 12.44 & 0.00 & 3.70 \\
\hline
\end{tabular}




\section{Pathogenicity test}

Some of the isolates were observed to be pathogenic and they included B. theobromae, Fusaruim sp., R. stolonifer, A. niger, and Penicillium sp. The $B$. theobromae induced the highest rot of $7.5 \mathrm{~cm}$ diameter within four days of inoculation followed by $R$. stolonifer which also induced rot of $3.5 \mathrm{~cm}$ within the same period while A. niger, Fusarium sp., and Penicillium sp.-induced rot of $2.2 \mathrm{~cm}, 1.8 \mathrm{~cm}$, and $1.0 \mathrm{~cm}$ (Table 3).

\section{Fermentation of soursop juice}

The $\mathrm{pH}$ was fluctuating from first to tenth day within the range of (4.2-4.5) indicating that soursop wine was fairly acidic (Figure 1). The alcohol content increased from first day to the tenth day (Figure 2). The alcohol content of the control at the end of tenth day fermentation $(9.3 \% \mathrm{v} / \mathrm{v})$ was lowest among other treatments (Table 1). Pasteurized and commercial yeast treatment gave the alcohol content of $(11 \% \mathrm{v} / \mathrm{v})$ while pasteurized and indigenous yeast treatment gave the highest alcohol content $(16.0 \% \mathrm{v} / \mathrm{v})$ on the tenth day (Table 4).

The yeast count increased from second day to the sixth day where it was highest and later decreased until the tenth day (Figure 3). This showed that fermentation was vigorous on the sixth day. There was reduction in the number of yeast cells from eight to tenth day and this might be as a result of the increase in the alcoholic content which killed the yeasts. Moreover, the increase in the number of yeasts from the second day of the sixth day indicated that the soursop juice supported yeast growth (Figure 3). The highest yeast count $4.84 \times 10^{2}$ colony forming unit per $\mathrm{ml}$ was recorded on the pasteurized and commercial yeast treatment on the sixth day (Figure 3).

\section{Physicochemical quality of soursop juice and soursop wine}

The moisture content $(87.49 \%)$ of the fruit juice increased compared with $97.9 \%$ in the wine (Table 5). The titratable acidity, fat, and alcoholic content increased in the wine

Table 3 Pathogencity test of some of the isolated fungi from both rotten and fresh fruits of Annona muricata

\begin{tabular}{ll}
\hline Fungi & Diameter of $\operatorname{rot}(\mathbf{c m})$ \\
\hline Botryodiploidia theobromae & 7.5 \\
Rhizopus stolonifer & 3.2 \\
Aspergillus niger & 2.2 \\
Fusarium sp. & 1.8 \\
Pencillium sp. & 1.0 \\
\hline
\end{tabular}

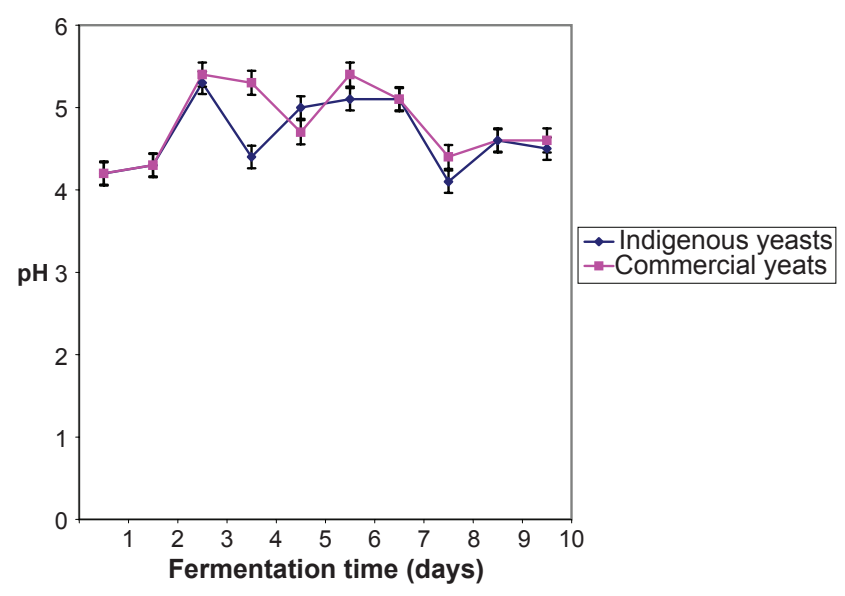

Figure I Changes in $\mathrm{pH}$ with time of fermentation of pasteurized juice in which indigenous and commercial yeasts were added.

(Table 5). Probably it might be as a result of the microbial activities as the fermentation progressed. The ash content decreased from $0.50 \%$ in the fruit juice to $0.23 \%$ in the wine (Table 5).

In addition, the crude fibre, protein, carbohydrate, vitamin $\mathrm{C}, \mathrm{pH}$, brix, and the specific gravity decreased in the wine when compared to the soursop juice (Table 5). This shows that microbial activity and processing affect the physical and chemical composition of the soursop juice. Moreover, the wine obtained was brown in color while the fruit juice was creamy white. This probably could be as a result of microbial activity during fermentation process. However, this improved the appearance of the soursop fruit juice by giving it a pleasant color.

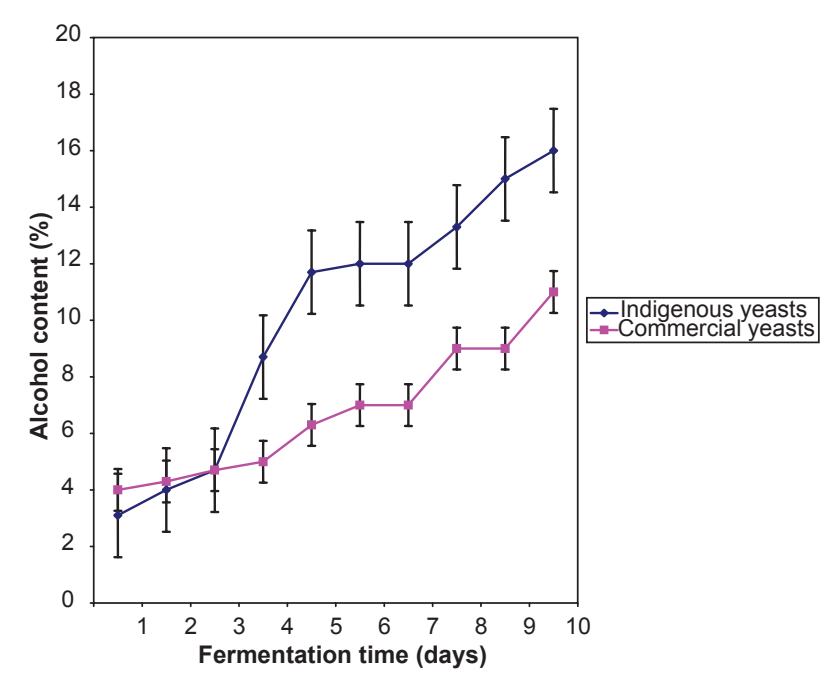

Figure 2 Changes in alcoholic content with time of fermentation of pasteurized juice in which indigenous and commercial yeasts were added. 
Table 4 Mean alcohol content of all the treatments at the end of ten days fermentation

\begin{tabular}{ll}
\hline Treatments & $\begin{array}{l}\text { Mean alcoholic } \\
\text { content \% (v/v) }\end{array}$ \\
\hline Pasteurized + Indigenous yeast & 16 \\
Natural + commercial yeast & 12.67 \\
Natural + No sugar + commercial yeast & 12 \\
Natural + sugar & 11.3 \\
Pasteurized + commercial yeast & 11 \\
Control & 9.33 \\
\hline
\end{tabular}

Furthermore, there was statistical evidence of significant different $(\mathrm{P}<0.05)$ among the alcohol content of the six treatments with the pasteurized and indigenous yeast treatment having the highest alcohol content.

\section{Organoleptic assessment}

The aggregate score of the five-person panel showed that the wine obtained was palatable and acceptable in terms of flavor, aroma, color, dryness, and sweetness. The flavor, color, and dryness were rated good, while the sweetness and aroma were fair.

\section{Discussion}

The research revealed that both the rotten and fresh fruits of soursop (Annona muricata L.) possess appreciable number of mycoflora in the juice, pulp, skin, and seed. The mycoflora isolated and observed coincides with other reports. ${ }^{3,13}$ There were more fungi isolated from the rotten fruit. This could be

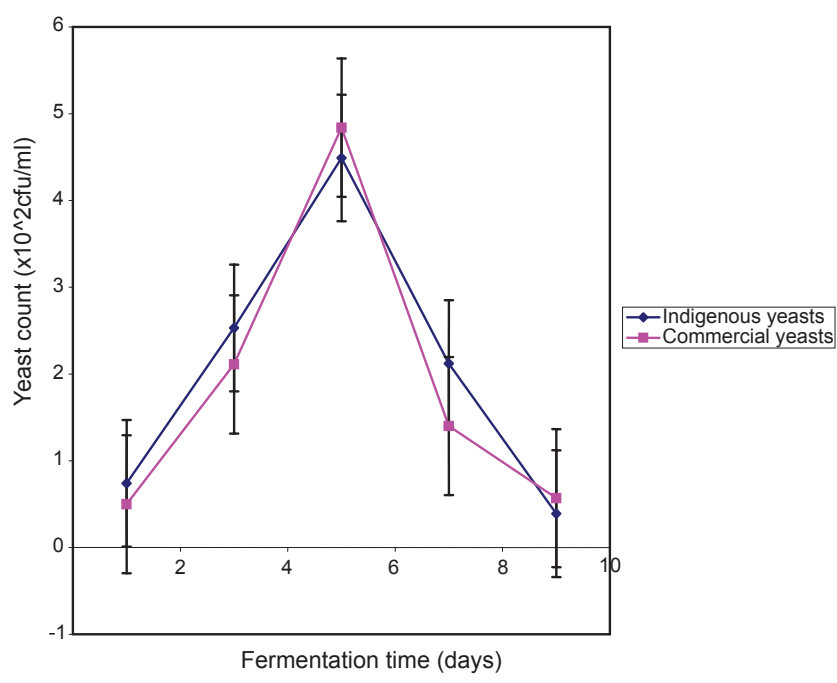

Figure 3 Changes in yeast count with time of fermentation of pasteurized juice in which indigenous and commercial yeasts were added. due to the fermentation processes taking place in the rotten fruit which favored yeast and other fungal growth, difference in moisture content of the fruits as well as the difference in the nutritional and chemical composition of the fruits. ${ }^{7,12,37}$ Similarly, the variations in fungi isolates among the fruit parts observed could be as a result of the difference in moisture content of each part. Mycoflora occurred more on the juice, pulp, skin, and seed in descending order.

It has been reported that moisture impacts effectiveness on fungal growth thus the juice with more moisture have more number of fungi. ${ }^{32}$ The work indicated also that $A$. niger had high incidence of occurrence than other isolates. This might be as a result of the ability of the fungus to sporulate faster in addition to being an airborne fungus, a secondary invader, as well as an opportunistic pathogen. ${ }^{38}$

The work equally shows that some of the isolated mycoflora were the causative agents of rot in fresh healthy fruits. ${ }^{13,39} \mathrm{~B}$. theobromae induced the highest rot. The involvement of Penicillium sp., A. niger, Fusaruim sp., and $R$. stolonifer in the deterioration of another tropical fruit, cashew (Anacardium occidentale) have long been identified. ${ }^{40}$ The association of Aspergillus flavus and A. tamirii in minute quantities is contrary to earlier work on mycoflora of groundnut seeds where their incidence were found to be high. ${ }^{41}$ Deterioration and rot of soursop fruits are caused by fungal pathogens.

It is generally known fact that wine is the alcoholic product of the fermentation of any fermentable fruit or vegetable by action of yeasts ${ }^{21}$ and various tropical fruits have been used for wine production. ${ }^{23,24,25,42}$ Wine can be obtained from soursop since they are rich in sugar and has acid $\mathrm{pH} .{ }^{7}$ The culture of Saccharomyces cerevisiae which was used utilized the sugar present in the juice and converted it to ethyl alcohol and carbon dioxide. During the fermentation process, it was observed that the alcoholic content increases as the fermentation day increases. This occurred as a result of daily breakdown of the sugar and subsequent conversion to ethyl alcohol. The soursop juice which was not ameliorated has the lowest alcoholic content $[9.3 \%(\mathrm{v} / \mathrm{v})]$. This was a consequence of low nutrient content of the juice. In addition, since the fruit juice was not pasteurized, it is likely that some other microorganisms were acting on the fruit juice thereby disrupting the yeast activity. When sugar was added as the only supplement in another fermenting juice, it gave a higher alcoholic content, indicating that the levels of nutrients for the yeasts to utilize have been increased. The pasteurized juice ameliorated with sugar, accessory nutrients and inoculated with indigenous yeast gave the highest alcoholic content 
Table 5 Physicochemical quality of fresh soursop juice and wine obtained

\begin{tabular}{lll}
\hline Parameters & Fruit juice & Fruit wine \\
\hline Moisture content (\%) & 87.49 & 97.9 \\
Ash content (\%) & 0.50 & 0.23 \\
Crude fiber (\%) & 3.29 & 0.58 \\
Fat (\%) & 0.03 & 0.2 \\
Protein (\%) & 0.63 & 0.31 \\
Carbohydrate (\%) & 8.06 & 0.78 \\
Alcohol (\%) & 0.0 & 14.5 \\
Vitamin C (mg/l00 ml) & 46.2 & 13.89 \\
pH & 4.8 & 4.5 \\
Titratable acidity (g citric acid/l00 g) & 0.03 & 0.06 \\
Brix $\left({ }^{\circ}\right)$ & 14.97 & 5.03 \\
Specific gravity & 1.03 & 1.01 \\
\hline
\end{tabular}

of $[16 \%(\mathrm{v} / \mathrm{v})]$. This alcoholic content is high, making the wine a strong wine, and it could be kept for a long time, ${ }^{43}$ thus the soursop juice is preserved. Many factors however, contributed to the high alcoholic level of this wine. Firstly, the pasteurization which is a process by which pathogenic organisms in the fluid is killed by heat. ${ }^{44}$ This indicates that lack of pasteurization is one of the major risks factors involved in fermentation. ${ }^{45}$ So it means that the pasteurization has killed the harmful microorganisms thereby drastically avoiding their toxic components. The importance of pasteurization cannot be overemphasized. The second factor is the addition of accessory nutrients which supplied nutrients to the yeast starter. Potassium dihydrogen orthophosphate and Ammoniun sulphate were suitable nitrogen sources, ${ }^{46}$ while sodium metabisulphite acted as a stabilizer and an antioxidant. ${ }^{24}$ The third and probably the most important factor that contributed to the high alcoholic content is the inoculation of the fruit juice with a culture of indigenous wine yeast. This shows that indigenous Saccharomyces cerevisiae from soursop juice can serve as yeast starter for wine production.

In addition, in fermentation of soursop juice with commercial yeast extract, the pasteurized and ameliorated soursop juice gave the alcoholic content of $[11 \%(\mathrm{v} / \mathrm{v})]$. But this is not as high and strong when compared with the wine obtained from pasteurized and ameliorated juice inoculated with culture of indigenous yeast flora. This observation coincides with the previous study on the use of Vitex doniana for wine production where the pasteurized and ameliorated juice inoculated with indigenous yeast flora gave the best win. ${ }^{24}$
Moreover, during the fermentation process, the yeast cell number was observed to increase as the fermentation day increases until the sixth day, when it was highest, and then it started to decrease. It has been reported that there was an increase in the number of Saccharomyces cerevisiae as the fermentation day increased until the fifth day, when it was highest and then started to decrease to a constant number. ${ }^{24}$ In addition, there was a high yeast activity during the primary fermentation. ${ }^{47}$ The increase in the number of yeast cell count as the fermentation day increases is associated with the utilization of the sugar content of the juice as fermentation proceeds thereby resulting in the growth of the yeast. Moreover, the occurrence of the highest number of yeast cells on the sixth day indicated that fermentation was vigorous on this day while the decrease after the sixth day is attributed to the increase in alcoholic content of the fermenting juice. This makes it obvious that yeast could not put up with a high alcoholic level. ${ }^{24,25}$ The increasing number of yeast cells per fermentation day indicated that soursop juice supports yeast growth and hence is a potential source of raw material for single-cell protein.

Furthermore, when the wine obtained from fermentation of soursop juice was physically and chemically analyzed to determine its nutritional composition, there was increase in the moisture, titratable acidity and fat content and decrease in the $\mathrm{pH}$, crude fibre, protein, carbohydrates, vitamin $\mathrm{C}$, sugar content, and specific gravity when compared with the fresh juice. These findings tallied with other earlier reports. ${ }^{15,24}$ Besides, the color of the wine was pleasant when compared with the soursop juice. These resulted from the microbial activities during fermentation processes, thereby indicating that processing affects the physical and chemical composition of soursop. ${ }^{7}$

\section{Conclusion}

With the number of isolated fungi from the different regions of soursop fruits, it can be concluded that different fungal species occur within both the rotten and apparently fresh healthy fruits of Annona muricata L. and that some of these fungal isolates especially Botryodiplodia theobromae have the potential to induce rot on fresh fruits which might have a remarkable effect on the value of the fruit especially in the food industry as well as on human health.

With regard to a palatable and acceptable wine obtained from fermentation of soursop juice which has a considerable high level of alcohol, the utilization of soursop juice for wine production is therefore recommended. Moreover, based on the level of nutritional composition of soursop and the ability 
to support the growth of yeasts, the use of soursop juice as a substrate for single-cell production is thus suggested.

\section{Acknowledgments}

Our appreciation goes to Chidozie Udechukwu, Emmanuela Onuora, and Chinelo A Ezeabara for their valuable contributions. The authors report no conflicts of interest in this work.

\section{References}

1. Samson JA. Tropical fruits. Singapore: Longman Publishers; 1980.

2. Morton JF. Fruits of warm climates. Coral Gables, FL: University of Miami; 1987.

3. Umme A, Salmah Y, Asbi BA. Microbial changes in natural soursop puree during storage. Food Chem. 1997;63:315-322.

4. Lutchmedial M, Ramlal R, Badrie N, Chang-Yen I. Nutritional and sensory quality of stirred soursop (Annona muricata L.) yoghurt. Int J Food Sci Nutr. 2004;55:407-414.

5. Anonymous. Soursop. 2007. Cited Dec 15, 2008. Available from: $\mathrm{http}: / /$ tropilab.com/soursop.html.

6. Taylor ML. Herbal secrets of the Rainforest "Tropical Plant Database". Miami, FL: Prima Publishing; 1998.

7. Abbo ES, Olurin T, Odeyemi G. Studies on the storage stability of soursop (Annona muricata L.) juice. Afr J Biotechnol. 2006;5:108-112.

8. National Academy of Science. Under exploited tropical plant with promising economic value. Washington, DC; National Academy of Science; 1978

9. Asprey GF, Thornton P. Medicinal plants of Jamaica. West Indian Med. 1995;4:69-92.

10. Bates RP, Moris JR, Candall PG. Principles and practices of small and medium scale fruit juice processing. FAO United Nations Newsletter. Rome, Italy: United Nations; 2001.

11. Aluko RE. Biochemical properties of some tomato fruit cultivars grown in northern Nigeria. Nigerian J Bot. 1989;2:157-164.

12. Okigbo RN. Mycoflora within black plum (Vitex doniana Sweet) fruit Fruits. 2000;56:85-92.

13. Amusa NA, Ashaye OA, Oladapo MO, Kafaru OO. Preharvest deteriorations of soursop (Annona muricata) at Ibadan South Western Nigeria and its effect on nutrient composition. Afr J Biotechnol. 2003;2:23-25.

14. Vyaya KP, Karana D. Determination of Cowpea seeds in storage by Aspergillus flavus. Indian Phytopathol. 1981;34:222-223.

15. Gow-Chin Y, Asin-Yan L. Microbial, enzymatic and chemical changes during storage of fresh and process orange juice. J Food Sci. 1996;57:1187-1197.

16. Singh P, Tanbson E, Buangusuwon D. Aflatoxin in maize in Thailand. Proc ACJAR. 1990;36:187-193.

17. Joffe AZ. The mycoflora of fresh and subsequently stored groundnut kernels on various soil types in Israel, J Bot. 1969;18:77-87.

18. Mc Donald D. Fungal infection of groundnut fruit after maturity and during drying. Trans Br Mycol Soc. 1970;54:461-472.

19. Tseng TC, Tu JC, Tzean SS. Mycoflora and mycotoxins in dry bean (Phaseolus vulgaris) produced in Taiwan and in Ontario, Canada. Bot Bull Acad Sin. 1995;36:229-234.

20. Laderberg J. Encyclopedia of Microbiology, vol. 2. San Diego, CA: Academic Press Inc; 1992.

21. Walker MB. Chambers Dictionary of Science and Technology. New York, NY: Chambers Herrap Publishers Ltd; 1999

22. Dutta AC. Botany for Degree Students. New York, NY: Oxford University Press; 2004.
23. Omole JO. Effects of peeling on the physicochemical properties of wine from carrot juice. Nigerian Food J. 2005;23:261-264.

24. Okigbo RN. Fermentation of black plum (Vitex doniana Sweet) juice for production of wine. Fruits. 2003;58:363-369.

25. Osho A. Evaluation of cashew apple juice for single-cell protein and wine production. Nahrung. 1995;39(5/6):521-529.

26. Tortora GJ, Funke BR, Case CL. Microbiology: An Introduction. Reading, MA: Addison Wesley Publishing Company Inc; 1992.

27. Osuide GE. Post-harvest losses implication for food quality and safety. In: Elemo GN, Editor. Post harvest loss reduction. Proceedings of 23rd Annual Conference of Nigeria Institute of Food Science and Technology, Abuja, Nigeria 1999. pp. 270-272.

28. Aniche OK. The Need for Post-harvest Physiology Application in Food Security Approach in Nigeria. Owerri, Nigeria: Food Science and Technology Federal University of Technologyi; 2003.

29. McDonald JK, Caffin NA, Sommano S, Cocksedge R. Effect of Postharvest Handling on Selected Native Food Plants. Barton, Australia: RIRDC Publication No 06/021; 2006.

30. Barnet HL, Hunter BB. Illustrated genera of imperfect fungi. Minneapolis, MI: Burgess Publishing Company; 1972.

31. Booth CH. Fusarium: Laboratory guide to the identification of major species. Kew, UK: Commonwealth Mycological Institute; 1977.

32. Buroughs R, Saver DB. Growth of fungi in Sorghum grains stored at high moisture contents. Phytopathology. 1971;61:767-772.

33. Lodder J. The yeast. A taxonomic study, 2nd edition. London, UK: North-Holland Publishing Company; 1971.

34. Association of Analytical Chemists. Official Methods of Analysis, 14th Ed. Horowits W., editor. Washington, DC: Association of Analytical Chemists; 1984.

35. Onwuka GI. Food analysis and instrumentation: Theory and Practice, First edition. Lagos, Nigeria: Naphthali Prints; 2005.

36. Gomez KA, Gomez AA. Statistical Procedures for Agricultural Research, 2nd ed. New York, NY: John Wiley and Sons; 1984.

37. Okigbo RN. Control of post-harvest of tropical fruits in Storage. Biotech Bioeng. 2005;7:69-84.

38. Raper KB, Fennell DF. The genus Aspergillus. Baltimore, MA: Williams and Wilkens; 1968.

39. Adisa VA, Fajola AO. Post harvest fruit rots of three species of citrus in southern Nigeria. Indian Phytopathol. 1982;35:595-603.

40. Olunloyo OA. Initiation and field prevalence of fungal rot of pseudo-apples of cashew in the plantation. Proceedings of the 22nd Annual Conference of Agricultural Society of Nigeria. Zaria, Nigeria; 1986.

41. Shittu GA, Umari D, Bawa M. Mycoflora associated with twovarieties of groundnut (Arachis hypogea L.) Nigerian J Bot. 2002;15:68-73.

42. Okunowo WO, Osuntoki AA. Quantitative of alcohols in orange wine ferment by four strains of yeast. Afr J Biotechnol Res. 2007;1:95-100.

43. Wineworld. 2002. Cited on Dec 15, 2008. Available from: http://www. wineworld.fdw.com.

44. Jawetz E, Melnick JL, Aldelberg EA. Review of Medical Microbiology. Los Altos, CA: Lange Medical Publications; 1980.

45. Food and Agriculture Organization (FAO). Fermented Cereals. A Global Perspective. FAO Agriculture Services Bulletin No. $138 ; 1999$.

46. Litchfield JH. Encyclopedia of microbiology, vol. 4. New York, NY: Academic Press Inc.; 1992.

47. Okorie O, Akobundu EN. Potential of soursop juice in wine production. Journal of Sustainable Agriculture and the Environment. 2001;3:310-314. 
